\title{
Evolution and future of total quality management: management control and organisational learning
}

Jens Jörn Dahlgaard, Lidia Reyes, Chi-Kuang Chen and Su Mi Dahlgaard-Park

The self-archived postprint version of this journal article is available at Linköping University Institutional Repository (DiVA):

http://urn.kb.se/resolve?urn=urn:nbn:se:liu:diva-160588

N.B.: When citing this work, cite the original publication.

This is an electronic version of an article published in:

Dahlgaard, J. J., Reyes, L., Chen, C., Dahlgaard-Park, Su Mi, (2019), Evolution and future of total quality management: management control and organisational learning, Total quality management and business excellence (Online). https://doi.org/10.1080/14783363.2019.1665776

Original publication available at:

https://doi.org/10.1080/14783363.2019.1665776

Copyright: Taylor \& Francis (Routledge) (SSH Titles)

http://www.routledge.com/ 


\title{
Evolution and Future of Total Quality Management: Management Control and Organizational Learning
}

\author{
Jens J. Dahlgaard \\ Professor, Department of Management and Engineering, Linköping University, Sweden \\ jens.jorn.dahlgaard@liu.se \\ Lidia Reyes \\ PhD Student, Department of Industrial Engineering and Management, Yuan Ze University, \\ Taiwan, s1058906@mail.yzu.edu.tw \\ Chi-Kuang Chen (corresponding author) \\ Professor, Department of Industrial Engineering and Management, Yuan Ze University, Taiwan, \\ ieckchen@saturn.yzu.edu.tw \\ Department of Industrial Engineering and Management, Yuan Ze University, \\ 135 Yuan-Tung Road, Chung-Li 320, Taiwan, ROC \\ Su Mi Dahlgaard-Park \\ Professor, Department of Service Management and Service Studies, Lund University, Sweden \\ sumi.park@msm.lu.se
}

\begin{abstract}
The competitive position achieved by the Japanese and Western industries during the 1970s to mid-1990s, and 1980s to mid-1990s, respectively, derived from understanding, implementing, and developing Total Quality Management (TQM) as a comprehensive management philosophy. Several research and/or company studies provided evidence of this development and its impact on leading companies' efficiency and effectiveness.

Despite that, research on TQM seemed on the surface, after a boom from about 1990 to 1995, to have declined. However, one recent detailed study from 2013 concluded that TQM is now at a more mature stage where focuses have shifted from being initially on TQM to the methods, tools, techniques and core values which are needed to implement TQM and to build a quality and BE (Business Excellence) culture.

This study is an extension of the 2013 study, where we extend the previous study on TQM publications to 2017, and further analyse more detailed not only which methods, tools and techniques are used, but also at what organisational level they are used - strategical, tactical or the operational level. We collect data on research about TQM and its methods, tools and techniques, and we analyse further the shift of focus from TQM as a comprehensive management
\end{abstract}


theory/ philosophy to a focus on the TQM methods, tools and techniques to be used at various management levels of a company.

We use two of management's basic functions - management control (MC) and organizational learning (OL) - to unveil the challenges faced by TQM and to help converting these challenges into new research opportunities to be jointly addressed by companies and research communities such as the Quality Management and Organisational Development (QMOD) Research Community.

In light of the findings in this research it became clear that $M C$ and $O L$ are two sides of the same coin. MC can never be effectively implemented without OL, and OL needs to be supported by a comprehensive MC system.

Keywords: Total Quality Management, Management Control, Organizational Learning, Strategic Quality Management

\section{Introduction}

The origins of the theory and practice of Total Quality Management (TQM) can be traced back to the 1920s where Walter Shewhart in 1924 began to apply statistical process control (SPC) in the Bell Telephone Company's Hawthorne Plant. He stated that SPC is a good way to learn and understand why and how performance changes over time (Lovitt, 1997). This adoption and promotion of SPC, which uses data as evidence of knowledge, helped to establish the importance of having a management control function and a related learning process as a necessary part of quality improvement efforts.

Later, in the 1950s and 1960s, the Japanese - with support from experts like W. Edward Deming, Armand V. Feigenbaum, Kaoru Ishikawa, and Joseph Juran - interpreted, understood, practiced, and further developed the concepts of SQC (Statistical Quality Control) and TQC (Total Quality Control). This term is coined by Feigenbaum (1961), and Prof. Ishikawa (Ishikawa, 1985 p. 91) who created the new term Company Wide Quality Control (CWQC) for the Japanese version of TQC. CWQC was further developed and re-branded in the West as TQM (Total Quality Management) during the 1980s (Dahlgaard-Park, 2013). The above mentioned quality experts/ gurus as well as others contributed and helped transitioning the movement from SQC to TQM carrying over the learning methodologies developed in Japan, such as the basic quality tools, quality control circles (QCC), and quality control stories (Gitlow, 1994). 
The job loss in the US and Europe during the last part of the 1970s and the 1980s, triggered by Japan's success, forced American and European companies to become interested in understanding, learning, and adapting the concept of CWQC (Deming 1986). This interest led to further academic research and the introduction of new principles, tools, and methods such as Business Excellence (BE), Six Sigma and Lean (Dahlgaard-Park, 2011; Lawler III et al., 1992; Port et al., 1992; Seymour \& Collett, 1991). Consequently, the principles and theories behind TQM evolved from quality inspection, quality control, quality assurance, and CWQC into the modern version of TQM, where the content expanded to include all functional areas of a business (Dahlgaard-Park et al., 2018; Dahlgaard et al., 2003).

As it evolved, TQM incorporated three managerial arenas: process management, human resource management, and strategic management. Thereby, TQM developed into a comprehensive management theory with multiple layers and elements/components within its framework, and many leading companies showed impressive results after having successfully implemented TQM (Dahlgaard-Park et al, 2018, pp. 1108-1128). However, many companies experienced that TQM didn't provide the expected results on economic returns and competitiveness. Hence, TQM lost its appeal for many company managers who started to use other competing managerial methods such as Balanced Score Card, Performance Management etc. hoping that they would give better results.

From the mid-1990s, research publications on TQM \& BE as a new and general management philosophy diminished drastically to the point where the number of articles published in 2011 was only one-third of those published in 1995 (Dahlgaard-Park et al., 2013). This was a surprise for many researchers within the quality management area because several large studies showed that it pays very well for companies to invest in those areas (Hendricks and Singhal, 1997; Boulter et al, 2013). Some researchers even proclaimed that TQM is dead or dying (no name references here).

However, as Dahlgard-Park et al concluded in their detailed research study to understand and explain the dramatic decrease in the number of research publication on TQM and BE (2013 p. 15):

"...we will also understand that data on the number of articles published on TQM and $B E$ are too narrow to conclude as above. Because TQM and BEM comprise multiple numbers of tools and techniques as well as culture and core values/principles then we should also collect 
and analyse data about these areas before we come up with a quick conclusion about the current state and expected future directions.

The results showed that the total number of articles under the subject of TQM has been decreasing since 1995 after having reached its peak. On the other hand, papers focusing on methods, tools and techniques within the QM framework, in terms of Self-Assessment, Lean, Six Sigma, SPC, Benchmarking etc. have been increasing. Papers focusing on the core values/principles needed to build a quality culture in terms of leadership, people-based management, continuous improvement, management based on facts, and customer focus have been slightly increasing during the last decade.

These findings indicate that TQM is now at a more mature stage where focuses have shifted from being initially on TQM to the tools, techniques and core values which are needed to implement TQM and build a quality and BE culture".

Trying to have all this in mind, this study aims to explain why research on TQM has changed its focus to especially methods, tools, techniques, and how this change of focus may affect the future of the quality movement.

We first do, in section 2, a timeline-based literature review of management control and organizational learning within the areas of TQM, regarding TQM as a sustainable long-term management approach derived from a set of values or principles that are control and learning oriented (Sitkin et al., 1994). Subsequently, in section 3, we analyse how research on management control and organizational learning have evolved in terms of the most popular TQM methods, tools and techniques. Discussions of the identified research trends will then follow in section 4 , and our final conclusions and recommendations will end up the article in section 5.

\section{Evolution of Management Control and Organizational Learning under TQM}

Management Control and Organization Learning processes are interdependent managerial processes that are seldom considered together in the TQM literature even if they should be regarded as two sides of the same coin. In the following literature review we will focus on when and how those two concepts evolved under the TQM evolution and try to find evidence or indications on the practice or non-practice of the two sides of the same coin principle. First, we will focus on the evolution related to the operational or process level, and after that we will focus on the organizational management level and then end up with some preliminary conclusions. 


\subsection{Operational (process) Level}

Management Control is a systematic process to define and implement performance standards to achieve organizational objectives. It is based on planning/ setting objectives and designing information feedback systems that help to find deviations and taking action to ensure that resources are used effectively and efficiently (Mockler, 1984, p.2).

The roots of MC go back to the basic principles of scientific management, where managers were engaged in planning, training, and follow up activities, allowing workers to perform their tasks, i.e. "to do" efficiently (Taylor, 1914). As Taylor sought to increase productivity and employees' skills while concurrently reducing waste, the further development of scientific management intertwined with the development of Statistical Quality Control (SQC).

The framework known as Operational Control (Robert, 1965) emerged when Japanese stakeholders understood the definition, meaning and practice of quality control: “... to develop, design, produce and service a quality product which is most economical, most useful, and always satisfactory to the consumer" (Ishikawa, 1985 p. 44).

Prof. Kaoru Ishikawa, who shaped the Japanese version of Total Quality Control (TQC), suggested quality control circles (QCC) and the seven basic quality improvement tools (7QC) to be used by the QCC members in their continuous suggestions for new process and product improvements. As said above, he coined in 1968 the new concept company-wide quality control (CWQC), a concept in which QC requires everybody's participation, in other words, participation of employees to become responsible for operational control (Ishikawa,1974; Martínez-Lorente et al., 1998).

Most of the methods, tools and techniques for product design and process improvement used today emerged from observing Japanese quality improvement procedures and best practices. For example, the Taguchi method (Taguchi, 1986), used for product design, applies statistical methods to ensure good performance in the design stage of products or processes. Hoshin Kanri (policy deployment) is a form of corporate-wide management technique that combines strategic management and operational management by linking the achievement of top management goals with daily management at the operational level (Kondo, 1995, p. 89). Hoshin Kanri is a framework for policy-based objectives that translates into QCDE (quality, cost, delivery, education) targets that drive progress (Witcher \& Butterworth, 2001). 
From this development another important concept/method emerged, operational learning, which is defined as learning at the process level, which helps to understand and describe "how to get things done around a specific process/task or project" (Hoffman \& Donaldson, 2004, p. 452).

\subsection{Organizational Management Level}

Organizational Learning (OL) is about an organization perceiving the environment and using its experience-based shared knowledge to adapt to changes and threats as well as defining future strategies. One of the most popular definitions of OL was provided by Senge (1990 p. 13-14), as: "a shift or movement of mind", where the environment is perceived differently by finding problems, proposing solutions, and recreating the organization's future.

Influenced by the focus mentioned previously, TQM was re-defined by several authors during the 1990s, and organizational learning (OL) was promoted more and more to the managerial level because the redefinition of TQM changed its theoretical scope and application. The new scope of TQM included more stakeholders (customers, employees, suppliers, business partners, and society), and its applications were widened to become more outcome or result oriented. New methods, tools and techniques such as Six Sigma, Self-assessment, Balanced Score Card, and Lean came into play and a more strategic and competitive perspective was applied (Svensson \& Klefsjö, 2006).

Peter Senge's book (1990) "The Fifth Discipline - The Art \& Practice of The Learning Organization" became a key contributor to this development, influencing EFQM (European Foundation for Quality Management) to change the wordings and other contents of the EFQM Excellence Model from 1997 to fit better to this development. For example, the feed-back loop from Results to Enablers in the 1997 model showed clearly the following two key words to address: Innovation and Learning (see Figure 1). 


\section{ENABELLERS}

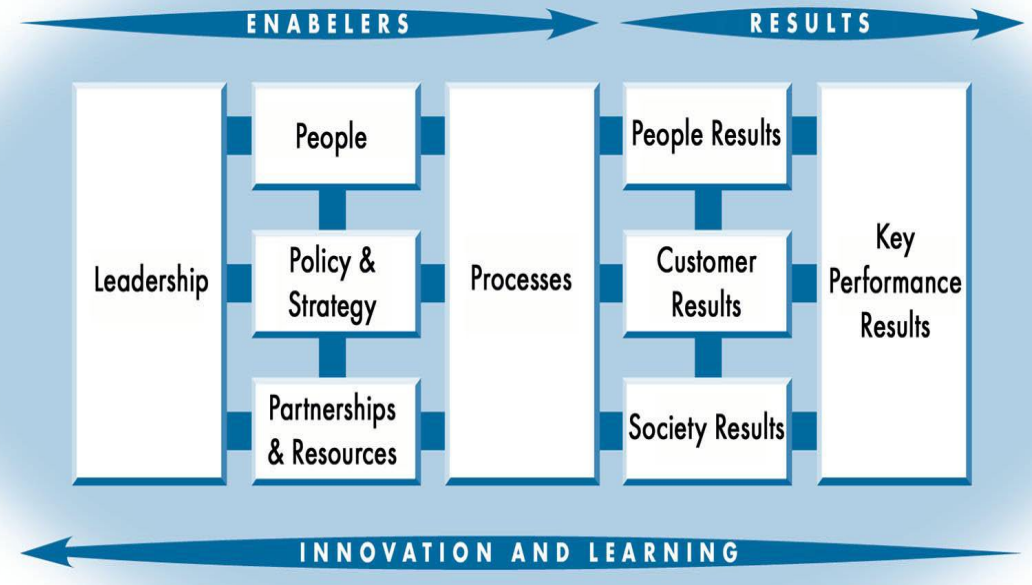

Figure 1: EFQM Excellence Model (1997)

In EFQM's 2013 version of the Excellence Model, shown in Figure 2, the importance of organizational learning (OL) was stressed even further, indicated by the feedback loop's focus on "Learning, Creativity, and Innovation". The importance of OL is shown furthermore in the subcriterions and potential areas to address.

However, the new mechanical logic, or rational orientation, from enablers to results tended to put aside the soft aspects of management such as organizational culture, values, people's motivation, training, and education (Dahlgaard-Park, 2011) even if the EFQM Excellence Models, as well as other leading excellence models such as the Malcolm Baldridge Model, requested a balance between the soft and the hard side of management as indicated in Figure 2. Companies worldwide adopted these new excellence models and its related methods, tools and techniques, and particularly the process of self-assessment (SA) as a learning mechanism to guide the development of quality improvement activities including innovation. 


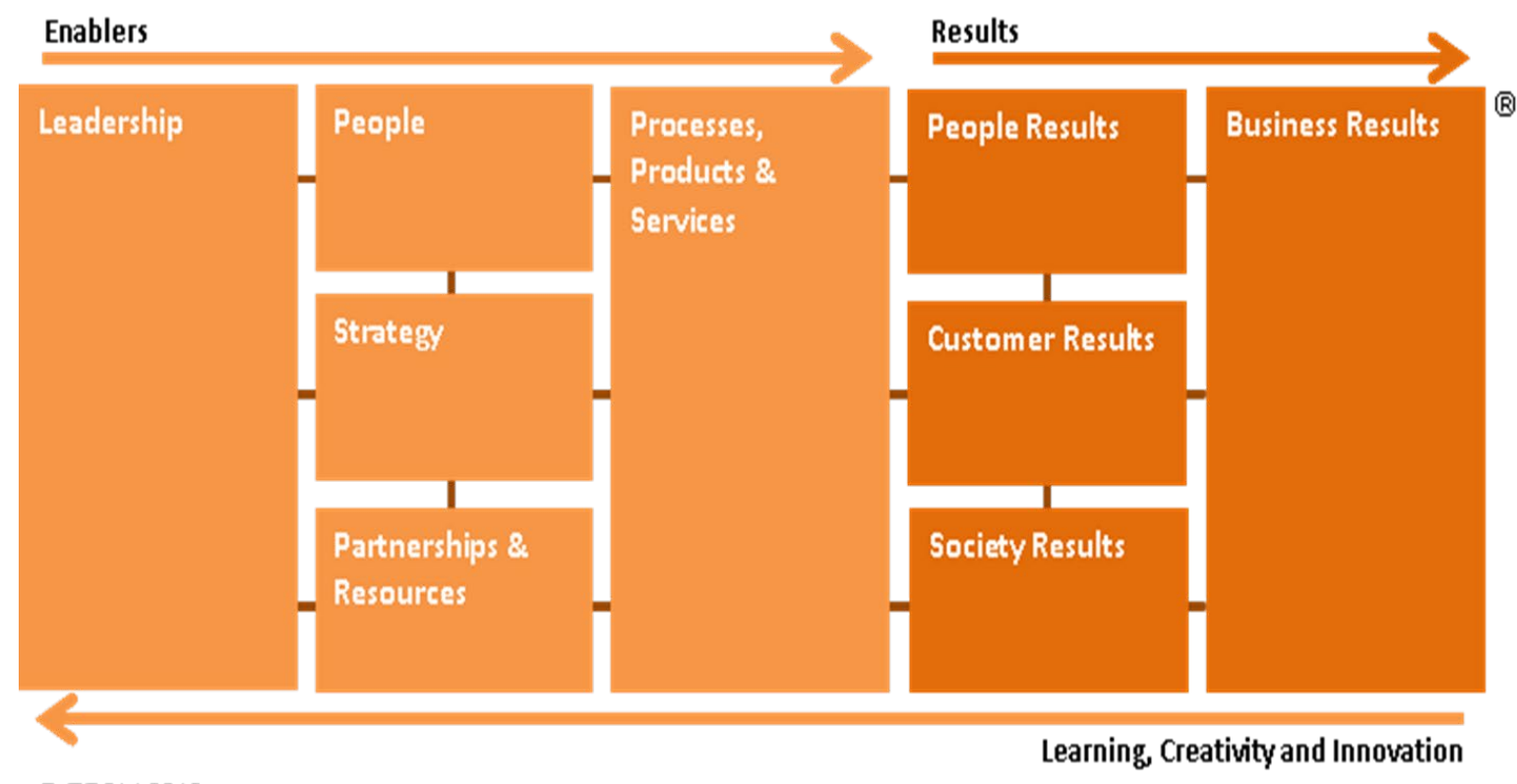

Figure 2: EFQM Excellence Model (2012/ 2013)

Self-assessment in TQM involves regular and systematic review of an organization's activities and performance supported by a quality/excellence framework such as the EFQM Excellence Model; however, this process tended to overemphasise measurements and resulted in a common misunderstanding of the TQM principles (Conti, 2010). Managers forgot that one of the most important ideas behind the adoption of TQM is the creation of a new organizational culture; practitioners as well as many researchers overlooked or even neglected to mention that the foundation for the successful application of all these new methods, tools and techniques is based on TQM and its core principles.

\subsection{Control and Learning - Concluding comments}

As seen from the above review, the way in which control and learning was understood, practiced and managed in Japanese versus western organizations, and more generally in excellent versus non-excellent organizations irrespective of origin, is in our view one of the main causes for the different TQM approaches used and the results achieved when companies tried to implement TQM.

The Japanese concepts of human relations and management focuses on employees' total participation for continuous process improvement (Khoo \& Tan, 2003) and QC specialists (Martínez-Lorente et al., 1998) conduct TQC/ CWQC implementation by focusing on employees' 
total participation. Most companies in the West focus on short term results rather than continuous process improvements (Harris, 1995); thus, employees' participation is weak in most companies, and managers are mostly the only responsible for improving quality (MartínezLorente et al., 1998). However, excellent companies irrespective of origin have learned the message that total participation is a TQM principle not to be negotiated, but must be learned and practiced.

In this learning process, control and learning share a relationship which many researchers have explained. For instance, Chen and Kuo (2011) concluded that organizational learning and quality improvement activities such as QCC are linked as facilitators, not as cause and effect methods. Similarly, Grigg \& Walls (2007) showed how statistical thinking and methods of control are related to organizational learning. They also stated that regardless of the industrial sector, the effectiveness of a control chart depends on having sufficient data. However, information from such techniques is seldom used to generate process knowledge, and hence learning loops are seldom completed. This finding connotes that there is a great need to integrate statistical thinking with organizational learning.

However, studies in this area have limitations and, so far, there is no specific literature focusing on management control and organizational learning from the perspective of TQM. In fact, based on the literature review stated above, since the focus shifted from operations/ process control and learning to organizational control and learning in the mid-1990s, research on TQM measured by the number of published research articles seems on the surface gradually to have lost its attractiveness. Why is that so? Is it because: "TQM is now at a more mature stage where focuses have shifted from being initially on the TQM Model/ management philosophy to the tools, techniques and core values which are needed to implement TQM and build a quality and BE culture"? (Dahlgaard-Park et al 2013 p. 15).

In order to further understand this mature stage, the next section will present statistics of the literature available on selected management control and organizational learning methods, tools and techniques used under the 'TQM umbrella'.

\section{Research trends in Management Control and Organizational Learning under TQM 3.1 Research methods}


Among the various research methods available, such as narrative literature review, meta-analysis, and systematic review methodology (SRM) (Baumeister \& Leary, 1997), we selected SRM because it's a systematic process of conducting literature reviews. We first defined the research scope, then examined databases, subsequently reviewed it and reported the results.

The research scope includes defining objectives, selecting databases, searching keywords, research protocols, and review criteria for the papers to be included. The main objectives are here to identify the research trends of: 1. TQM quality improvement methods, tools and techniques used for management control and organizational learning, 2. TQM and Business Excellence (BE) as separate topics, and 3. To provide insightful reasons about the changes found during the last five years of the study period (2013-17).

To achieve those objectives, we searched through almost half a century of literature using keywords (See Table 1) that relate to TQM's areas of study and influence, and performed statistical analysis on the results. Due to comprehensive databases of the relevant literature, we selected the ProQuest ABI/Inform Collection as a search instrument. It includes in-depth coverage from thousands of publications, with $80 \%$ of them in full-text and more than 6,800 journals, including the most important business journals from leading publishing companies such as Cambridge University Emerald Group Publishing, Springer, and MIT Sloan School of Management, among others. The articles selected were based on the document title and keywords that represent, at a practical level, the study areas analysed in this research, and articles were selected from peer-reviewed scholarly journals only.

The analysis of the data is focusing on the management level and the methods, tools and techniques that are commonly used at each level. The following three typical management levels of an organization were used in this study: The strategic (SML), tactical (TML) and operational management level (OML), where each of these three levels uses different TQM methods, tools and techniques.

Table 1. Data collection from ProQuest ABI/Inform database (1973-2017)

\begin{tabular}{lc}
\hline Key-words & No. of articles \\
\hline Self-Assessment (SA) & 452 \\
\hline Lean & 1853 \\
\hline Six Sigma & 1029 \\
\hline Process Control Chart (PCC) & 180 \\
\hline Statistical Process Control (SPC) & 188 \\
\hline
\end{tabular}


The selected methods, tools and techniques play important roles as connectors to achieve effectiveness and efficiency from the top strategic level to the tactical and the operational levels, and those three levels offer an opportunity to explain systematically the analysis of the data collected.

The strategic management level (SML) involves the continuous planning, monitoring, analysis and assessment of all necessary areas for an organization to meet its aim and goals (where does the organization want to go), and selecting the areas that should be improved and setting the goals for improvements. Self-Assessment is the TQM method to be applied at this level. The tactical management level (TML) involves the selection of appropriate ways and means of achieving the strategic plan (how to get there), and this is where the Six Sigma and Lean tools and techniques are to be applied. Finally, the operations management level (OML) involves planning, organizing, and supervising processes and making the necessary improvements to increase competitiveness and profitability (the detailed work related to the overall plans). This is where SPC and PCC together with other tools and methods may be applied.

\subsection{Research trends}

Table 2 presents the total number of articles relevant to each tool and technique published in time intervals of 5 years between 1973 and 2017.

Table 2. Number of articles per time period and keyword

\begin{tabular}{ccccccc}
\multicolumn{7}{c}{$\mathbf{1 9 7 3 - 2 0 1 7}$} \\
\hline Time interval & $\begin{array}{c}\text { SPC } \\
(\mathrm{OML})\end{array}$ & $\begin{array}{c}\text { PCC } \\
(\mathrm{OML})\end{array}$ & $\begin{array}{c}\text { Six-Sigma } \\
(\mathrm{TML})\end{array}$ & $\begin{array}{c}\text { Lean } \\
(\mathrm{TML})\end{array}$ & $\begin{array}{c}\text { SA } \\
(\text { SML })\end{array}$ & Total \\
\hline $1973-1977$ & 0 & 0 & 0 & 2 & 3 & 5 \\
$1978-1982$ & 0 & 2 & 0 & 2 & 9 & 13 \\
$1983-1987$ & 0 & 1 & 0 & 7 & 14 & 22 \\
$1988-1992$ & 0 & 6 & 1 & 17 & 28 & 52 \\
$1993-1997$ & 0 & 22 & 5 & 140 & 54 & 221 \\
$1998-2002$ & 58 & 19 & 137 & 141 & 86 & 441 \\
$2003-2007$ & 59 & 41 & 367 & 349 & 85 & 901 \\
$2008-2012$ & 41 & 50 & 357 & 610 & 77 & 1135 \\
$2013-2017$ & 30 & 39 & 162 & 585 & 96 & 912 \\
Total & 188 & 180 & 1029 & 1853 & 452 & 3702 \\
\hline SPC $=$ Statistical Process Control; PCC $=$ Process Control Chart; SA $=$ Self-assessment
\end{tabular}


If we first look at the total number of articles published in each period, we see significant increases every period from 1978 to 2012, where only 5 articles were published in the first period (1973-1977) and a total of 1135 articles were published in the second last period (20082012). We can also observe that the last period showed a significant decrease of $19.6 \%$ but the total number was still higher than the period 2003-2007. We can also see that, of the 3,702 published articles considered for the study, 368 articles (9.95\%) belong to operational management learning level (OML), 2882 articles (77.85 \%) belong to the tactical management level (TML) and 452 articles (12.20\%) belong to the strategic management level (SML).

Prior to 1978, the number of publications in the operational tools SPC and PCC were zero, the tactical tool Lean cropped up with two articles and the strategic tool SA with three articles. In the next 10 years (1978-1987) we see that the interest for doing research in those areas increased slowly except that SPC and Six-Sigma were not yet represented in the statistics.

The next 10-year period (1988-1997) shows a very strong increase in publications related to SA, Lean and PCC especially related to the last five years of this period but SPC is still represented with zero publications. The next 10-year period (1998-2007) is characterised with having publications on SPC for the first time and with an impressive growth from zero publications to a total of 117 publications. For the other tools we see the same explosion in the number of publications, where the top-scorers were Six Sigma with 504 publications and Lean with 490 publications.

After 2007 the next period of only 5 years showed a beginning decrease in SPC, Six Sigma and SA while Lean almost doubled from 349 publications to 610 publications, and the last 5-years period (2013-2017) is characterised by a decrease in all areas except SA which increased the number of publications from 77 to 96 . The most dramatic decrease was the Six Sigma area which experienced a reduction over 5 years from 357 to 162 publications while Lean only had a moderate decrease and continued to stay at the relatively high level of 585 publications. The changes of research focus will be discussed further below supported by Table 2 and Figures 3 and 4 .

In the first two decades (1973-1992) shown in Figure 3, TQM knowledge in the western countries was lagging, which explains the low number of research studies up to 1980. After that, US and other leading western countries started slowly to wake up, and research interest in Six Sigma, Lean and SA began to surge. 
The amount of published research shows that past the mid-1980s a new phase of quality control and management began in the western countries with the creation of new concepts and approaches. As a result, companies began re-examining the quality control techniques that were used successfully during the past 30 years by the Japanese. However, unlike the Japanese version with a different cultural approach, the western quality movement focused on the tactical and the strategic management levels (TML and SML) by providing education and training to middle and/or top-level managers instead of emphasizing the entire company. As a result, western companies were showing a lack of integration among the three management levels.

Referring to Figure 3, which shows the number of articles published on quality management tools and techniques during the period 1973-2017, it is noticed that most of the research has been done after 1993, increasing substantially during the mid-90s. However, after 2012, research in all the subjects, except SA, decreased, and the last five years (2013-2017) research on PCC/SPC decreased by $24 \%$, Six Sigma by $55 \%$, and Lean by $4 \%$; with the notable exception being SA, which actually increased by $20 \%$.

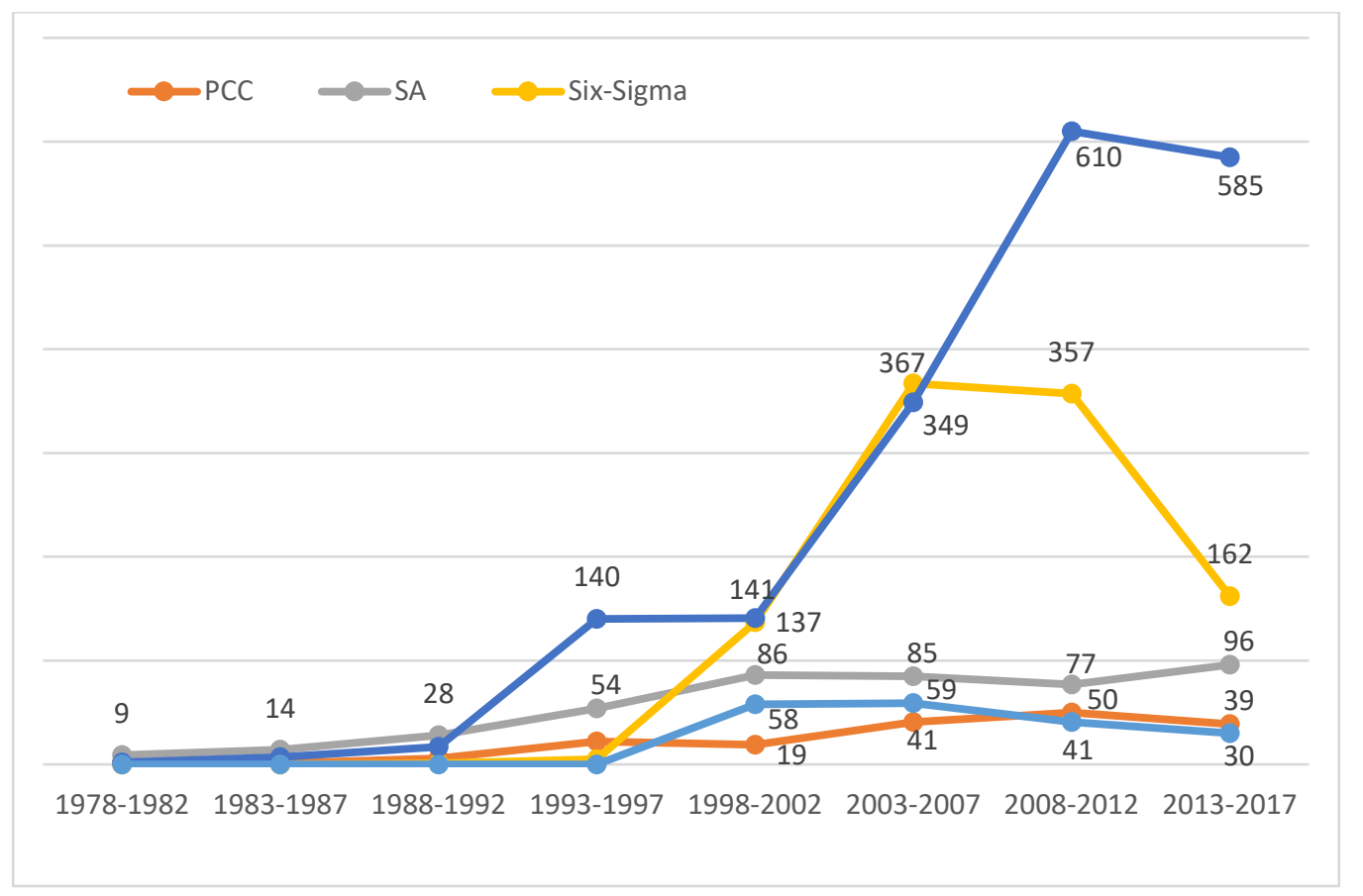

Figure 3. Keyword-based articles published per study area.

Dahlgaard-Park et al (2013) analysed the TQM and BE research trend from 1987 to 2011, a 25 -year period, and in this study we do a continuation of the analysis until 2017. As shown in Figure 4, the total number of articles published on TQM was 2080, compared to 405 articles 
published on $\mathrm{BE}$ during the same period. The highest number of publications on TQM was in 1995 (203 articles) and for BE in 2002 (35 articles).

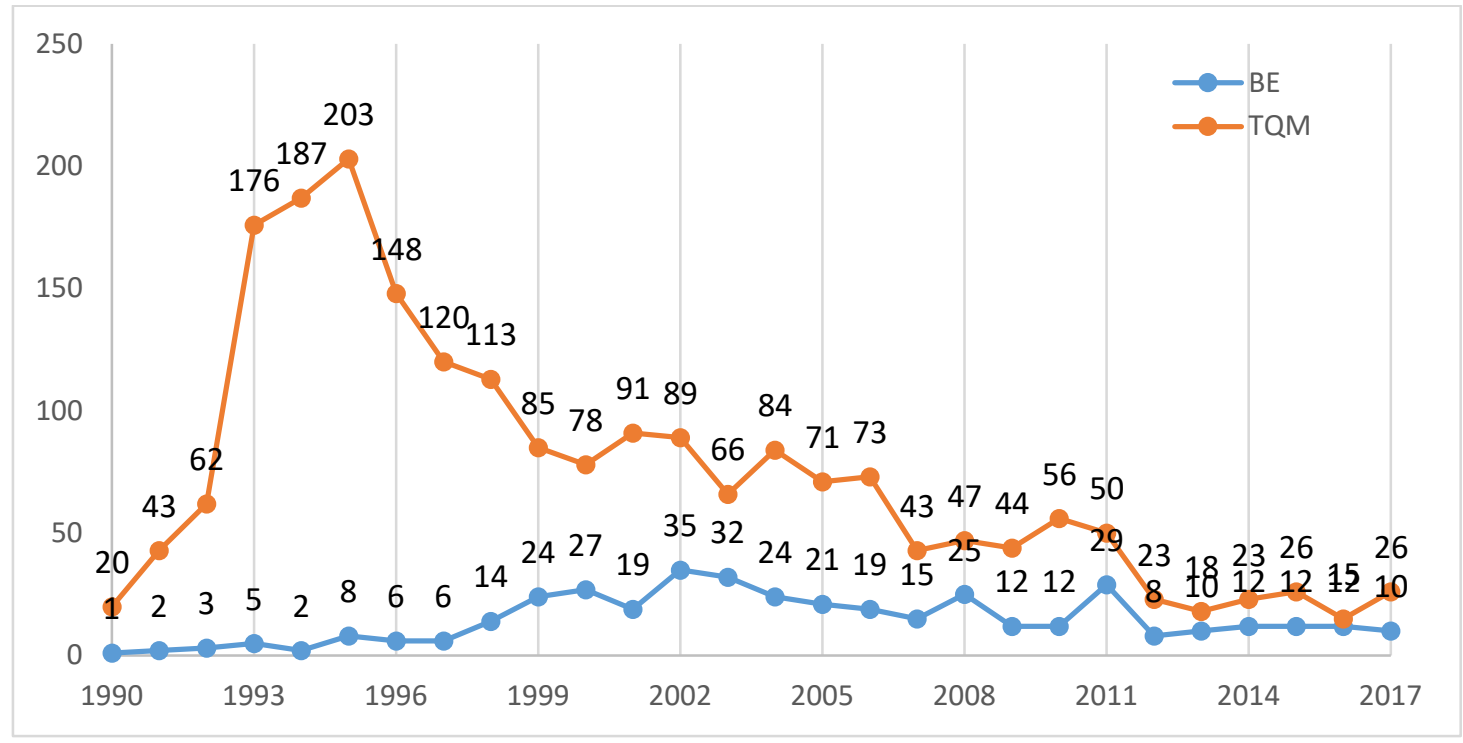

Figure 4. Frequency chart for articles published under TQM and BE (1990-2017) 
Our further discussion here in this section focuses on the research developed during the past six-year period (2012-2017), where the number of articles with TQM or BE in the title showed a decreasing trend compared to the previous 6-year period, thereby demonstrating a weakening or further loss of appeal for general TQM and BE subjects. This may indicate a lack of a profound systems-knowledge which may affect connections between the three management levels upsetting the organizational controlling and learning processes discussed in Section 2 and researched further in this section with a focus on selected TQM methods, tools and techniques (see Figures 2 and 3).

To complement our research above we also did qualitative content analysis. The process consisted in collecting data from the ProQuest ABI/Inform database (2012-2017) using the search terms: Total Quality Management and Business Excellence in the title of the articles. In total 230 articles were found and among of them, we focused on the 10\% (24) most cited articles, considering these the vital few articles that have attracted the most attention from the academic community. The subject categorization was defined based on the title and abstract reading, and if it was still unclear a further reading was conducted. As a result, the 24 articles were categorized into the following four major research subject areas.

First, the research focused on the use of BE frameworks for TQM implementation (Calabrese \& Corbò, 2015; Chuang et al., 2015; Metaxas \& Koulouriotis, 2014).

Second, the research focused on the relational analysis of TQM/BE with organizational culture (Alotaibi, 2014; Fellague \& Bennafla, 2015; Gimenez-Espin et al., 2013; Sinha \& Arora, 2012).

The third type of research focused on the impact/effect of TQM/BE implementation on business performance (Iyer et al., 2013; Rashid \& Haris Aslam, 2012; Sadikoglu \& Olcay, 2014; Talib et al., 2013).

Finally, the fourth type of research focused on the influence of TQM/BE in different business areas or industries such as supply chains, education, health, and construction (Altinok, 2016; Claude Ah-Teck \& Starr, 2014; Loke et al., 2012; Rashid \& Haris Aslam, 2012). 


\section{Discussions}

In light of the research trends analysed above, and the content analysis of 24 articles selected from the last six years of our study we intend to make further discussions related to the following three aspects: 1 . the research trend in the three management levels of quality methods, tools and techniques under TQM; 2. the research trend in TQM and Business Excellence (BE); 3. the importance of Strategic Quality Management (SQM).

\subsection{Research trend in quality methods, tools and techniques}

With regard to the first aspect, it follows from Figure 3 as well as Table 2 that, the amount of research related to the tactical management level of TQM (TML), which is represented by Six Sigma and Lean, and the operational management level of TQM (OML), represented by SPC and PCC, are much higher than the amount of research at the strategic management level of TQM (SML), represented by SA. Why is that so?

An explanation may be that organizations have encountered difficulties in their use and application of the above methods, tools and techniques, indicating that companies, and maybe researchers too, do not understand that operational and tactical learning (OML and TML) can only be effective and efficient if the learning process is wisely guided by learning at the strategic management level of the company (SML). Therefore, this interpretation gives an indication that more research needs to be done in strategic learning (SML) with a quality management orientation. In other words, there is a need for research in Strategic Quality Management (SQM), an important area of TQM, which, for unknown reasons, is undeveloped and in our view is almost unknown by researchers and top managers in all kind of industries.

Figure 3 shows that the tactical methods, Six Sigma and Lean, attracted the interest of academicians during the period 1998-2012, after which Six Sigma lost its appeal and Lean experienced stagnation but still remains at a high level. Based on previous sections, this loss of appeal in Six Sigma was perhaps because companies didn't get the results they expected after maybe too high level of promotion by consultants or researchers (Arthur, 2009).

Another explanation could be the high complexity of implementing the methodologies of Six Sigma. The implementation of these methodologies is difficult because they're relatively sophisticated, demand higher levels of knowledge, and require overcoming a series of challenges 
during their application by ordinary workers. Thus, implementation cannot be considered a straightforward process because the implementation of six-sigma methodologies requires that all employees are educated and trained by experts to become a kind of expert (black belts, green belts or white belts), and employees, as well as managers, are going through personal learning curves while applying the methodologies. This will only work if there is a strong management support and commitment; therefore, time and financial support are important factors that should be considered (Lodgaard et al., 2016). In this massive education there are risks that the training of people will focus too much on training people in statistical tools, and there is too little emphasis on understanding the human factor (Dahlgaard \& Dahlgaard-Park, 2006), teamwork, motivation, value adding, and sharing of knowledge (Lodgaard et al., 2016). Such risks are high if the implementation is lacking strategic support meaning that the overall strategic direction is unclear or missing.

To explain why the interest in Lean is still at a high level, a reasonable explanation is that the following five principles for reducing waste and building lean enterprises (Womack and Jones, 1996 p.10; Dahlgaard and Dahlgaard-Park, 2006 p. 268) are easy to understand by managers and employees, and furthermore easy to relate to top-managers' strategic thinking and focus.

(1) Specify value by specific product;

(2) Identify the value stream for each product;

(3) Make the value flow without interruptions;

(4) Let the customer pull value from the producer;

(5) Pursue perfection.

\subsection{Research trend in TQM and Business Excellence}

Based on the content analysis of 24 published research articles from the last 6-year period we found that:

1. On one hand, the analysed research studies focused on the promotion of how important learning is in a TQM organization. Greater levels of TQM practices tend to enhance knowledge of management practices and, therefore, organizational learning, as proved by findings of Jiménez-Jiménez et al. (2015), Lee and Lee (2014), and Loke et al. (2012). They also highlight that the successful implementation of TQM in different industries rely on values such as total 
participation based on proper education and training. This leads to team work, continuous improvement, corporate quality culture, customer focus, and a combination of management techniques under a quality management system (Fu et al. 2015; Goh 2015; Mosadeghrad 2015).

2. On the other hand, the research contents on TQM and BE over the last six-year period lead us to conclude that the challenges of TQM are related to adjusting and modifying the QM framework, while continuously developing better tools and techniques to fit the needs of new services and knowledge-intensive organizations.

3. The content analysis also showed that TQM has been successfully implemented in multiple industries, demonstrating that TQM is still an important area of research that still attracts the interest of academicians as well as managers from different sectors. As DahlgaardPark et al. (2013 p. 15) state, "QM is at a more mature and advanced level, spreading to all types of industries and the public sector. And successful top leaders have found that practice of TQM enhances organizational control and learning, enriches management knowledge, and improves quality performance".

4. However, our main finding is that there are strong indications for a disconnection between the three management levels - strategic, tactical and operational level - that further may have triggered the disintegration between management control (MC) and organizational learning (OL) under TQM. Such disconnection/disintegration has two significant impacts.

Firstly, it hinders the cultivation of TQM's core principles: management by fact, management commitment, customer focus, people-based management, continuous improvement and, most of all, total participation. Total participation is a key factor of excellent business performance because it encourages employees to innovate and help the company to maintain its long-term vision and planning. Companies need to demonstrate the importance of team work and generate interdepartmental cooperation; recognise employees' efforts by giving them individual goals, empower them to participate in decision making, help them to grow in their careers and, most of all, encourage total participation. This helps to build a TQM culture needed for positive business performance (Fu et al., 2015).

Secondly, it may have foiled the academic development and integration of MC and OL perspectives into TQM, leaving aside the continuous development of TQM as an organizational theory. 


\subsection{The importance of Strategic Quality Management}

With the above background it is no surprise that studies in Strategic Quality Management (SQM) is still at a very early stage. A simple and logical explanation is that if companies/company managers haven't understood that they really need to improve their yearly strategy process with an increased focus on strategic aspects of quality (SQM) then it is difficult for researchers to select this research area because empirical data is missing or difficult to find. Instead researchers select research topics from available ones such as Business Excellence (BE), Self-assessment (SA) and Lean because those topics may be close related to SQM.

For instance, self-assessment (SA) is an important method to be applied at the strategic management level, that, combined with other tools and methods such as benchmarking and TQ audits, helps to understand the current situation of a company (where are we now?) and sets the plans for quality improvements (where do we want to go?). However, SA could also be applied for both short and long-term goals; therefore, it is evident that SA needs also to be used at the tactical level (TML) to bridge the gap in relation to the strategic management level (SML).

In the same way Lean and Six Sigma are tools and methods that connect with SA at the tactical level (TML). But, Lean and Six Sigma should also go further down to the operational level (OML) connecting with SPC and PCC and many other tools and techniques at the operational level. However, such work logic may only become established when quality is included from the strategic to the operational level. This work logic translates into an overlap of the three management levels to identify meaningful opportunities for improvements and guarantee that everyone in an organization works towards common goals (Dahlgaard et al., 2008).

\section{Conclusions}

Our findings in this article lead us to conclude that the concept TQM as a general management theory has gradually lost its research appeal since the mid1990s, and the focus has changed to a new focus on the application of the TQM methods, tools and techniques. Dahlgaard-Park et al (2013) explained this change of focus as a natural evolution to a more mature state of the TQM evolution caused by the challenges and problems which companies experienced when trying to implement TQM. Companies need better strategic roadmaps complemented with suitable methods, tools and techniques to assure success with their implementations. 
There are several reasons for that need but one main finding in this research indicate that a root cause may be the negative effects of disintegration of management control (MC) and organisational learning (OL) methods. The disintegration between MC and OL may result in short term objectives, lack of systematic implementation and understanding that a system needs an objective or aim (vision, mission and goals), interrelated components, and continuous improvement (information/ learning/ knowledge). Moreover, managers need to understand the importance of building a suitable organizational culture with a focus on the TQM basic principles which is a must be activity in the pursuit of BE.

Thus, future research should focus more on Strategic Quality Management (SQM), but with the understanding that $M C$ and $O L$ are two sides of the same coin; this means that $\mathrm{MC}$ and OL are closely related to each other and must not be separated. Using strategic learning through Self-assessment (SA) organizations can learn quickly from their work, so they can learn from, and adapt, their strategies to ensure that the tactical and operational levels are learning as well, demonstrating effective and efficient performance.

In light of the above arguments, the authors believe that the same formula - management control and organizational learning - is applicable and ready to be applied as a core methodology for in any type of organisation. Building the right organizational culture with the top, middle, and shop-floor employee's active involvement and commitment, appropriate company structure and resource support helps to improve the effective implementation of TQM practices. It strengthens core values, management by fact, continuous improvement, and peoplebased management, nourishing teamwork, mutual trust, and collaboration, all of which lead to total organizational participation.

As a management theory, it might seem after a first look on the statistics in figure 4 that TQM has lost its appeal, but this is only because the look was too quick and 'viewers' did not 'look' on all components under the TQM umbrella. When looking especially on the evolution of the TQM methods, tools and techniques we agree totally by the conclusion by Dahlgaard-Park (2013, p. 15) that "TQM is now at a more mature stage" where focuses have shifted from being initially on TQM to the methods, tools, techniques and core values which are needed to implement TQM and to build a quality and BE culture. This research supports this conclusion and shows not only light on what methods had the highest focus during the different evolution 
stages of the study period, but also new and better light on what organizational levels those methods, tools and techniques are useful to be applied.

\section{REFERENCES}

Alotaibi, F. M. S. (2014). Impact on quality culture of total quality management practices factors. International Journal of Business and Economic Development, 2(3), 35-48.

Altinok, P. (2016). An evaluation on effects of total quality applications in customer relations management on sustainable global competition. International Journal of Research in Business and Social Science, 3(1), 35-62.

Arthur, J. (2009). If Six Sigma is so easy, why isn't everyone doing it? Quality Digest, 2019(01/04).

Baumeister, R. F., \& Leary, M. R. (1997). Writing narrative literature reviews. Review of General Psychology, 1(3), 311-320.

Boulter, L., Bendell, T. \& Dahlgaard, J.J. (2013) Total quality beyond North America: A comparative analysis of the performance of European Excellence Award winners, International Journal of Operations \& Production Management, Vol. 33:2, 2013.

Calabrese, A., \& Corbò, M. (2015). Design and blueprinting for total quality management implementation in service organisations. Total Quality Management \& Business Excellence, 26(7-8), 719-732.

Chen, I. C., \& Kuo, M.-H. C. (2011). Quality improvement: perspectives on organizational learning from hospital-based quality control circles in Taiwan. Human Resource Development International, 14(1), 91-101.

Chuang, S.-S., Chen, K.-S., \& Tsai, M.-T. (2015). Exploring the antecedents that influence middle management employees' knowledge-sharing intentions in the context of total quality management implementations. Total Quality Management \& Business Excellence, 26(1-2), 108-122.

Claude Ah-Teck, J., \& E. Starr, K. (2014). Total quality management in mauritian education and principals' decision-making for school improvement: "Driven" or "informed" by data? Journal of Educational Administration, 52(6), 833-849.

Conti, T. (2010). Systems thinking in quality management. The TQM Journal, 22(4), 352-368.

Dahlgaard-Park, S. M. (2011). The quality movement: where are you going? Total Quality Management \& Business Excellence, 22(5), 493-516.

Dahlgaard-Park, S. M. (2011). The quality movement: where are you going? Total Quality Management \& Business Excellence, 22(5), 493-516.

Dahlgaard-Park, S. M., Chen, C.-K., Jang, J.-Y., \& Dahlgaard, J. J. (2013). Diagnosing and prognosticating the quality movement- A review on the 25 years' quality literature (1987-2011). Total Quality Management \& Business Excellence, 24(1-2), 1-18.

Dahlgaard-Park, S. M. (2015). The SAGE Encyclopedia of Quality and the Service Economy: SAGE Publications.

Dahlgaard-Park, S. M., Reyes, L., \& Chen, C.-K. (2018). The evolution and convergence of total quality management and management theories. Total Quality Management \& Business Excellence, 29(9-10), 1108-1128.

Dahlgaard, J. J., Kanji, G. K., \& Kristensen, K. (2003). Fundamentals of total quality management: Routledge. 
Dahlgaard, J. J., \& Mi Dahlgaard-Park, S. (2006). Lean production, six sigma quality, TQM and company culture. The TQM magazine, 18(3), 263-281.

Dale, B., Zairi, M., Van der Wiele, A., \& Williams, A. (2000). Quality is dead in Europe-long live excellence-true or false? Measuring Business Excellence, 4(3), 4-10.

Evans, R. (1995). In defence of TQM. The TQM magazine, 7(1), 5-6.

Feigenbaum, F.E. (1961). Total Quality Control - Engineering and Management, McGraw-Hill, New York, US.

Fellague, M., \& Bennafla, K. (2015). Organizational culture and the implementation of total quality management in SONATRACH (MEDGAZ project and case study). Indian Journal of Management Science, 5(1), 1.

Frederick, T. (1911). The Principles of Scientific Management. New York: Harper Bros, 5-29.

Fu, S.-L., Chou, S.-Y., Chen, C.-K., \& Wang, C.-W. (2015). Assessment and cultivation of total quality management organisational culture-an empirical investigation. Total Quality Management \& Business Excellence, 26(1-2), 123-139.

Gimenez-Espin, J. A., Jiménez-Jiménez, D., \& Martínez-Costa, M. (2013). Organizational culture for total quality management. Total Quality Management \& Business Excellence, 24(5-6), 678-692.

Gitlow, H. S. (1994). A comparison of Japanese total quality control and Deming's theory of management. The American Statistician, 48(3), 197-203.

Goh, A. B. (2015). ROFO principle generates ownership, commitment and team learningmindset change before implementing total quality management. Total Quality Management \& Business Excellence, 26(7-8), 854-874.

Grigg, N., \& Walls, L. (2007). The role of control charts in promoting organisational learning. The TQM Magazine, 19(1), 37-49.

Harris, C. R. (1995). The evolution of quality management: an overview of the TQM literature. Revue Canadienne des Sciences de l'Administration, 12(2), 95-105.

Hendricks, K. and Singhal, V. (1997), "Does implementing an effective TQM program actually improve operating performance? Empirical evidence from firms that have won quality awards", Management Science, Vol. 43 No. 9, pp. 1258-74

Hoffman, K. G., \& Donaldson, J. F. (2004). Contextual tensions of the clinical environment and their influence on teaching and learning. Medical education, 38(4), 448-454.

Ishikawa, K. (1974). Guide to Quality Control. Asian Productivity Organisation, Tokyo.

Ishikawa, K. (1985). What is Total Quality Control? - The Japanese Way. Prentice-Hall, Engleewood Cliffs, N.J., US.

Iyer, A., Saranga, H., \& Seshadri, S. (2013). Effect of quality management systems and total quality management on productivity before and after: Empirical evidence from the Indian auto component industry. Production \& Operations Management, 22(2), 283-301.

Jiménez-Jiménez, D., Martinez-Costa, M., Martínez-Lorente, A. R., \& Rabeh, H. A. D. (2015). Total quality management performance in multinational companies: A learning perspective. The TQM Journal, 27(3), 328-340.

Khoo, H. H., \& Tan, K. C. (2003). Managing for Quality in the USA and Japan: Differences Between the MBNQA, DP and JQA. The TQM Magazine, 15(1), 14-24. Lawler III, E. E., Mohrman, S., \& Ledford Jr, G. E. (1992). The fortune 1000 and total quality. The Journal for Quality and Participation, 15(5), 6.

Kondo, Yoshio (1995). Companywide Quality Control - Its Background and Development. 3 A Corporation, Tokyo. 
Lee, H.-H., \& Lee, C.-Y. (2014). The effects of total quality management and organisational learning on business performance: evidence from Taiwanese insurance industries. Total Quality Management \& Business Excellence, 25(9-10), 1072-1087.

Lodgaard, E., Ingvaldsen, J. A., Gamme, I., \& Aschehoug, S. (2016). Barriers to lean implementation: Perceptions of top managers, middle managers and workers. Procedia CIRP, 57, 595-600.

Loke, S.-P., Downe, A. G., Sambasivan, M., \& Khalid, K. (2012). A structural approach to integrating total quality management and knowledge management with supply chain learning. Journal of Business Economics \& Management, 13(4), 776-800.

Lovitt, M. R. (1997). The new pragmatism: going beyond Shewhart and Deming. Quality Progress, 30(4), 99-105.

Martínez-Lorente, A. R., Dewhurst, F., \& Dale, B. G. (1998). Total quality management: origins and evolution of the term. The TQM Magazine, 10(5), 378-386.

Masters, R. J. (1996). Overcoming the barriers to TQM's success. Quality Progress, 29(5), 53-55.

Mosadeghrad, A. M. (2015). Developing and validating a total quality management model for healthcare organisations. The TQM Journal, 27(5), 544-564.

Metaxas, I., \& Koulouriotis, D. (2014). A theoretical study of the relation between TQM, assessment and sustainable business excellence. Total Quality Management \& Business Excellence, 25(5-6), 494-510.

Miyagawa, M., \& Yoshida, K. (2005). An Empirical Study of TQM Practices in JapaneseOwned Manufacturers in China. International Journal of Quality \& Reliability Management, 22(6), 536-553.

Mockler, R.J. (1984); The Management Control Process, Prentice-Hall, Englewood Cliffs, NJ, US

Nichter, S., \& Goldmark, L. (2009). Small firm growth in developing countries. World Development, 37(9), 1453-1464.

Nwabueze, U. (2001). How the mighty have fallen: the naked truth about TQM. Managerial Auditing Journal, 16(9), 504-513.

Port, O., Carey, J., Kelly, K., \& Forest, S. A. (1992). Quality: small and midsize companies seize the challenge-not a moment too soon. Business Week, 30 (November).

Rashid, K., \& Haris Aslam, M. (2012). Business excellence through total supply chain quality management. Asian Journal on Quality, 13(3), 309-324.

Robert, A. (1965). Planning and Control Systems. A Framework for Analysis. Boston: Graduate School of Business Administration, Harvard University.

Sadikoglu, E., \& Olcay, H. (2014). The effects of total quality management practices on performance and the reasons of and the barriers to TQM practices in Turkey. Advances in Decision Sciences, 2014,17.

Schimpff, S. C., \& Rapoport, M. I. (1997). Ownership and governance of university teaching hospitals: Let form follow function. Academic Medicine: Journal of the Association of American Medical Colleges, 72(7), 576-588.

Senge, P. (1990). The Fifth Discipline. The Art \& Practice of Learning Organization. New York, NY: Currency Doubleday.

Seymour, D., \& Collett, C. (1991). Total Quality Management in Higher Education: A Critical Assessment. Methuen, MA: ERIC.

Sinha, A., \& Arora, B. (2012). Fit between organizational culture and business excellence: A case study of heavy electrical equipment plant, BHEL. Vikalpa, 37(3), 19-28. 
Sitkin, S. B., Sutcliffe, K. M., \& Schroeder, R. G. (1994). Distinguishing control from learning in total quality management: A contingency perspective. Academy of Management Review, 19(3), 537-564.

Svensson, M., \& Klefsjö, B. (2006). TQM-based self-assessment in the education sector: Experiences from a Swedish upper secondary school project. Quality Assurance in Education, 14(4), 299-323.

Taguchi, G. (1986). Introduction to Quality Engineering: Designing Quality into Products and Processes. Asian Productivity Organization, Tokyo.

Taylor, F. W. (1914). Scientific Management: Reply from Mr. F. W. Taylor. The Sociological Review, 7(3), 266-269.

Talib, F., Rahman, Z., \& Qureshi, M. (2013). An empirical investigation of relationship between total quality management practices and quality performance in Indian service companies. International Journal of Quality \& Reliability Management, 30(3), 280-318.

Witcher, B. J., \& Butterworth, R. (2001). Hoshin Kanri: Policy management in Japanese-owned UK subsidiaries. Journal of Management Studies, 38(5), 651-674.

Womack, J. P., \& Jones, D. T. (1996). Lean Thinking - Banish Waste and Create Wealth in your Corporation, Simon \& Schuster, London. 